\title{
Marked Increases in Background Photon Emissions in Sudbury Ontario More than One Week before the Magnitude $>$ 8.0 Earthquakes in Japan and Chile
}

\author{
Michael A. Persinger, Ghislaine F. Lafreniere, Blake T. Dotta \\ Laurentian University, Sudbury, Canada \\ Email: mpersinger@laurentian.ca
}

Received March 27, 2012; revised May 3, 3012; accepted June 1, 2012

\begin{abstract}
Daily, minute-to-minute measurements of ground level photon emissions in Sudbury, Ontario Canada displayed conspicuous increases more than one week before the 2011 M9.0 earthquake in Japan and the 2010 M8.8 earthquake in Chile. Temporal profiles of the antecedent increase and subsequent decline in power densities for the two events were remarkably similar. Antecedent changes for $7.0<\mathrm{M}<7.9$ events during the same period were evident but more subtle. The results suggest the possibility that protracted increases in background photon emissions may precede major $(\mathrm{M}>$ 8.0) seismic events anywhere on the planet.
\end{abstract}

Keywords: Photon Emissions; Seismic Events; Earthquake Antecedents

\section{Introduction}

Forecasting of major seismic events is one of the most challenging problems in the contemporary geosciences [1-3]. Antecedent measurements, including anomalous increases in hydrogeochemical, electromagnetic, and macroscopic luminous phenomena, have occurred hours to days before some seismic events [4-11]. Considering the complexity and numerous mechanisms likely involved with the myriad processes that might contribute to these phenomena, such heterogeneity would be expected.

Most of the traditional forecasting indicators [2,7-10] have been related to regional seismic events that were proximal to the sensor of the instrumentation. The major limitation of these antecedents has been their locality and inconsistency. A second problem is the records may not be available in real time but are only revealed after the event. Consequently their utility for preparing, at least in principle, for the event is limited.

If very energetic earthquakes, such as $M>8$, that can be detected globally and generate inordinate local structural damage and loss of human life could have a universal indicator for anticipation, then preparatory strategies might be more effectively coordinated. We have been searching for indicators by which one could estimate prudently the imminent occurrence of major energetic releases. Our theoretical approach is that specific changes in the amplitudes of background photon emissions might reflect global stresses that predominantly contribute to unexpectedly large magnitude earthquakes.

To test this hypothesis we had been recording photon emissions per minute by a photomultiplier tube (PMT) $24 \mathrm{hr}$ per day for about two years within our basement environment. The purpose has been to test the involvement of background photon fluctuations in both biophysics studies $[12,13]$ and transient geomagnetic anomalies [14]. Our background power densities were relatively stable during quiet periods, between $10^{-12}$ and $10^{-11}$ $\mathrm{W} / \mathrm{m}^{2}$, with each unit increase representing about $5 \times$ $10^{-11} \mathrm{~W} / \mathrm{m}^{2}$.

During the months preceding the 9.0 magnitude 11 March, 2011 earthquake and tsunami that occurred in Japan our daily measurements had been stable and predictable. Then, for more than two weeks the photon emission values exhibited erratic variations whose amplitudes increased over successive days. As the energy density began to diminish, the devastating geophysical phenomena in Japan occurred. When we compared the photon emission pattern with the one that was stored in our archival photon data collected around the time of the Chilean quake the previous year, a marked similarity was evident. We present this clear congruence here.

\section{Methods and Materials}

For the last two years daily background photon emissions have been recorded by a RCA electron tube (photomultiplier tube, PMT) with no filters housed in a BCA IP21 
unit (aperture $=12.56 \mathrm{~cm}^{2}$ ) kept in a black wooden box covered with $10 \mathrm{~cm}$ of dark cloth in a windowless dark basement room. The output from the PMT was transformed to $\mathrm{mV}$ (millivolt meter) for a Model 15 Photometer from SRI instruments (Pacific Photometric Instruments). The output from the PMT through the photometer was recorded and visualized once per min by an IBM Thinkpad laptop (Windows 95). Both the photometer and the laptop computer were kept in a separate room.

With a sensitivity of 1500 for the photometer and an input current of $0.01(\max =0.001)$, values within the midpoint (50) were obtained for the meter (1 to 100 units) and the coupled laptop recording. Calibration by three different methods $[12,13,15]$ to verify quantitative congruence indicated that an increase of 1 unit was equivalent to an increase of $\sim 5 \times 10^{-11} \mathrm{~W} / \mathrm{m}^{2}$. The methods included photon emissions from known quantities of bioluminescent chemical reactants (hydrogen peroxide and sodium hypochlorite) and inverse-square law applications of light emitting diodes with known emissions from $10 \mathrm{~m}$ distance. Means and medians for the 1440 minutes that composed the daily values were obtained from the printed graphs for each day and transferred to PC SPSS 16 software for graphing and analyses.

\section{Results}

Our measurements for the days before, during, and after the Japanese quake are shown in Figure 1. It shows the median numbers of units per day. The median number for each day was from 1440 values, i.e., numbers of minutes, per day $[12,13]$. The correlation between the daily median and mean values was 0.98 indicating the consistency of the intradaily measures. About 24 days before the March event there was an abrupt increase in ambient photon power density that was maintained for about a month. The peak, which would be equivalent to about 350 times the photon density over our background reference range, occurred 7 to 11 days before the major shock. The return to baseline ranges occurred about 15 to 16 days later.

These observations were so exceptional and conspicuous that we examined our PMT data files since our measurements began for the previous $\mathrm{M}>8$ magnitude event that had occurred in Chile on 27 February 2010 (M $=8.8$ ). These measurements are also shown in Figure 1 (open circles). The units refer to the same absolute magnitude of photon power density. Again there was an abrupt and maintained increase in photon emissions that began about 12 days before the main shock. The peak in the photon emission increase occurred between 6 and 8 days before the event followed by a gradual return to baseline levels about 13 days later (days with missing data were involved with cell measurement experiments).

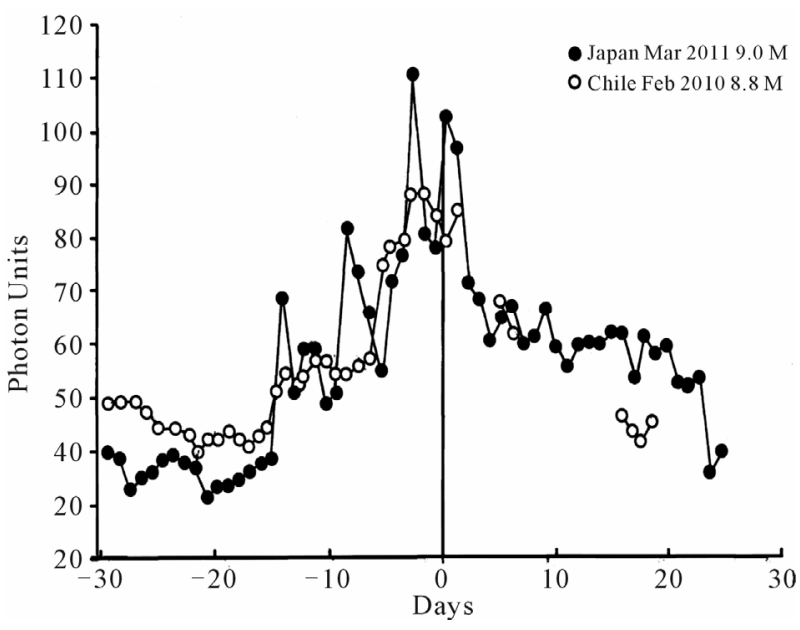

Figure 1. Median daily numbers of photon units $(1$ unit $=5$ $\times 10^{-11} \mathrm{~W} / \mathrm{m}^{2}$ ) recorded by our photomultiplier tube system (1 sample/min, $24 \mathrm{hr} /$ day) during the days before, during, and after the Japanese (closed circles) and Chilean (open circles) very strong earthquakes.

Both the events in Chile and Japan showed diminishment of the peak about one week before the main shock.

Because the changes were so extreme and only occurred before these two major earthquakes, that is, never at any other time during the two years of monitoring, statistical analyses were considered not applicable. Given that the daily mean and standard deviation for background measures during "quiet periods" were about 42 and 3 photon units, respectively, the peak photon power densities that occurred before the strong quakes were more than 8 standard deviations (z-scores) above that mean.

\section{Discussion}

The conspicuous antecedent increases in continuous photon emissions for days before the quakes were $\sim 9200$ $\mathrm{km}$ and $\sim 9700 \mathrm{~km}$ (surface distance) away from the Chilean and Japanese events, respectively, and suggest that very energetic seismic events may be preceded by ground photon emissions at a global level. Other EM phenomena such as radio waves have been detected at large distances in similar time frames for other great earthquakes [14]. Whether or not any locality on the earth's surface can discern these changes remains to be explored.

Our PMT station is located in a basement of the Arts Building on the Laurentian University campus which is located near the major ore body (a very likely ancient meteor impact site) in Sudbury, Ontario. The multiplecovered PMT sensor is housed in a darkened room that is adjacent to the original surface rock that was not disturbed when the building was constructed. Our seismographic sensor (Hilger \& Watts SG450), utilized to 
monitor rockbursts and local events [15], is within $30 \mathrm{~m}$ in a separate room. It's location on the bed rock with the sensitivity setting $(\mathrm{db}=24)$ was sufficient to clearly detect all events of $\mathrm{M}>6.0$ that followed the Chilean and Japanese quakes on our Sprengnether Instrument Co. unit and RV-301 helicorder.

Close scrutiny of the daily photon emissions around the days of 7 magnitude quakes as verified by U.S.G.S. data bases during this same period displayed some evidence of antecedent elevations. However these were more subtle and many were so close to the baseline fluctuations that confident prognostications would be more difficult. Recent [16] analyses of recondite spectral patterns within minute-to-minute daily fluctuations in photon emission amplitudes over a one year period from our station revealed potential global coupling to seismic and atmospheric oscillations that are usually in the order of $10^{-12}$ to $10^{-11} \mathrm{~m} \cdot \mathrm{s}^{-2}$ within the 2 to $7 \mathrm{mHz}$ range. Whether or not the additional consideration of these patterns might increase accuracy of forecasting major earthquakes remains to be tested.

\section{Acknowledgements}

The authors thank Dr. John Derr for his advice and guidance and Mr. Brendan Lehman for technical assistance.

\section{REFERENCES}

[1] F. T. Freund, "Toward a Unified Solid State Theory for Pre-Earthquake Signals," Acta Geophysica, Vol. 58, No. 5, 2010, pp. 719-766. doi:10.2478/s11600-009-0066-x

[2] R. Rikitake, "Earthquake Prediction," Elsevier, Amsterdam, 1976.

[3] M. Wyss, "Can Earthquakes Be Predicted?" Science, 1997, Vol. 238, p. 487.

[4] A. Bernardi, A. C. Fraser-Smith, P. R. McGill and O. G. Villard, "ULF Magnetic Field Measurements Near the Epicenter for the $\mathrm{M}_{\mathrm{s}}$ 7.1 Loma Prieta Earthquake," Physics of the Earth and Planetary Interiors, Vol. 68, No. 1-2, 1991, pp. 45-63. doi:10.1016/0031-9201(91)90006-4

[5] J. S. Derr, "Earthquake Lights: A Review of Observations and Present Theories," Bulletin of the Seismological Society of America, Vol. 63, No. 6, 1973, pp. 2177-2187.

[6] J. S. Derr and M. A. Persinger, "Luminous Phenomena and Seismic Energy in the Central United States," Journal of Scientific Exploration, Vol. 4, No. 1, 1990, pp. 5569.

[7] G. Igarashi, S. Saeki, N. Takahata, K. Sumikawa, S. Tasaka, Y. Sasaki, M. Takahashi and Y. Sano, "Ground Water Radon Anomaly before the Kobe Earthquake in Japan," Science, Vol. 269, No. 5220, 1995, pp. 60-64. doi:10.1126/science. 269.5220 .60

[8] L. M. Fishkova, M. M. Gokhberg and V. A. Pilipenko, "Relationship between Night Airglow and Seismic Activity," Annales Geophysicae, Vol. 3, 1985, pp. 689-694.

[9] T. M. Ralchovsky and L. M. Komarov, "Periodicity of Earth Electric Precursors before Strong Earthquakes," Tectonophysics, Vol. 145, No. 3-4, 1988, pp. 325-327. doi:10.1016/0040-1951(88)90204-1

[10] E. A. Roeloffs, "Hydrologic Precursors to Earthquakes: A Review," Paegoph, Vol. 126, No. 2-4, 1988, pp. 177-209. doi:10.1007/BF00878996

[11] T. Terada, "On Luminous Phenomena Accompanying Earthquakes," Bulletin of the Earthquake Research Institute of Tokyo University, Vol. 9, 1931, pp. 225-255.

[12] B. T. Dotta, C. A. Buckner, R. M. Lafrenie and M. A. Persinger, "Biophoton Emissions from Cell Cultures: Biochemical Evidence for the Plasma Membrane as the Primary Source," General Physiology and Biophysics, Vol. 30, 2011, pp. 301-309.

[13] B. T. Dotta and M. A. Persinger, “'Doubling' of Local Photon Emissions When Two Simultaneously SpatiallySeparated Reactions Share the Same Magnetic Field Configurations," Journal of Biophysical Chemistry, Vol. 3, No. 1, 2012, pp. 72-80. doi:10.4236/jbpc.2012.31009

[14] J. W. Warwick, C. Stoker and T. R. Meyer, "Radio Emission Associated with Rock Fracture: Possible Application to the Great Chilean Earthquake of May 22, 1960," Journal of Geophysical Research, Vol. 87, No. 4, 1982, pp. 2851-2859. doi:10.1029/JB087iB04p02851

[15] M. A. Persinger and B. T. Dotta, "A Transient but Protracted Geomagnetic Anomaly in the Sudbury Basin Following Two Near-Contiguous Intense Geomagnetic Storms," International Journal of Geosciences, Vol. 2, No. 3, 2011, pp. 363-365. doi:10.4236/ijg.2011.23038

[16] M. A. Persinger, "Annual Variations of Local Photon Emissions' Spectral Power within the $\mathrm{mHz}$ Range Overlaps with Seismic-Atmospheric Acoustic Oscillations," International Journal of Geosciences, 2012, in Press. doi:10.4236/ijg.2012.31021 